\title{
Earthquake resistant characteristics of traditional Khasi houses in Shillong, India
}

\author{
B. I. O. Dahunsi \& A. K. Mittal \\ Structural Engineering Division, Central Building Research Institute, \\ India
}

\begin{abstract}
Shillong, the capital of the state of Meghalaya, is located in the highest risk zone (V) of earthquake vulnerability in India. The area has witnessed several earthquakes including the one that occurred in 1897 during which most of the town was destroyed. Some of the buildings that survived the earthquake included some traditional Khasi houses. The earthquake resistant features of such traditional buildings were studied. Basically, the traditional Khasi houses are built on raised platforms. The roofs are of thatch while the walls may be from materials such as stone masonry with lime mortars, lime rendered mud walls or thatch depending on prevailing weather conditions. Mud and stone walls are common in areas with heavy rainfalls. The structural system consists mainly of post and beam timber frames having pillars buried into the ground. The floor is supported at intervals by limestone or wooden pillars. Some of the characteristics of the traditional Khasi houses in Shillong that are in conformity with modern building code requirements include the fact that they are not usually built on hill tops and they have symmetrical oval shapes which are devoid of sharp corners, thereby avoiding stress concentrations which is a major source of failure at wall corners during earthquakes. Nails are not used in the constructions, and the grooves and tongues that are utilized allow for dissipation of seismic loads. The roofs are made of light materials so that fatalities from failed roofs are limited. Earthquake resistant features exist in traditional constructions in Shillong, which could be useful in building better earthquake resistant houses in modern times, especially for rural and urban poor settlements in earthquake prone countries.

Keywords: building codes, earthquake, earthquake resistant characteristics, Khasi houses, Shillong, traditional construction.
\end{abstract}




\section{General background}

Shillong is the capital city of the state of Meghalaya in the North Eastern part of India. It came into prominence in 1864 when the district headquarters of the Khasi and Jaintal Hills was transferred from Sohra (Cherapunji). Prior to this, it was a small village situated on the site of a thousand year old Khasi habitat. Rapid growth in population and buildings took place in the town when in 1874 it was chosen as the headquarters of Assam province. Legend has it that the town got its name from U'Lei Shillong, one of the deities worshipped by the people in earlier times, believed to reside on the Shillong peak, the highest point in the city.

Shillong is located in the highest risk zone (V) in terms of earthquake vulnerability in India. Seismically, the area is one of the most active in the world. The area has witnessed several earthquakes including the one that occurred in 1897 during which the town was completely destroyed. The magnitude of the earthquake was estimated at around 8.7. Ambraseys and Bilham [1] described it as the largest intraplate event in the last two centuries in India. Satyabala [2] reported that the destruction was universal as every bit of solid stonework including most bridges was leveled to the ground. The few surviving buildings were wood framed ones and even some of these were destroyed by falling elements from stone chimneys. Excessive liquefaction was observed to be a common feature of the earthquake.

Some of the major buildings destroyed during the earthquake included the chief commissioner's residency, houses of leading administrators and several churches. Several traditional buildings built of wood were reported by residents to have withstood the earthquake in interviews by this author in the cause of this investigation. These buildings are mainly in the rural areas of the town. Examples of this form of traditional construction can still be found at several locations around Shillong and Cherrapunji. The physical and structural characteristics of the traditional and conventional constructions in Shillong and adjoining areas were studied with a view to evaluate their earthquake resistant features.

\section{Methodology}

This study was carried out through personal interviews and the use of structured questionnaire administered on occupants of traditional and also conventional constructions in Shillong, India and adjoining areas. The questionnaires were in English but interpretation in local languages was provided for respondents when necessary. Archival materials from government offices were consulted while discussions with architects, engineers, artisans, and other building professionals were held. Field trips were made to identify and study the physical and structural features of traditional houses of the Khasi people of India. 


\section{Results and discussions}

\subsection{General description of traditional Khasi houses in Shillong}

Basically the traditional Khasi houses of Shillong and adjoining areas are oval or egg-like shaped, somewhat resembling an overturned boat. Some natives related the similarity to egg as being linked to the traditional belief that egg is a source of life and that the eggshell offered protection for the content of the egg just as the traditional houses offer protection for its occupants. The layouts of the building are as show in Figure 1. The buildings are generally built on raised platforms. The roofs are of thatch while the walls may be from materials such as stone masonry with lime mortars, lime rendered mud walls or of thatch depending on prevailing weather conditions. Mud and stone walls are common in areas with heavy rainfalls, as thatch deteriorates quickly in such conditions. Figure 2 illustrates the side view of a typical grass walled and roofed traditional Khasi building while the front view is shown in Figure 3. An upgraded traditional house is shown in Figure 4. It has lime rendered mud walls and corrugated iron roofing sheets.

The traditional Khasi building system of the Shillong plateau was followed in the construction of the Iing Sad (The building housing the queen mother; mother of the traditional Khasi chief and a custodian of the matrilineal culture of the people). The building though built with technical skills commensurate with modern building construction practices and professional supervision, replicates the methods, materials and structural forms used in traditional constructions (Figure 5). Hence, it was used in this present study in several instances to explain the structural form of the traditional Khasi construction system.

The first portion of the house is the entrance, which in most cases is roofed. From the entrance one move into the Shyngkup whose function is like a verandah and separates the main living areas from outside. The wall at the end of the Shyngkup known as Shah Ksew (first plank) is the last part of house where dogs and other domestic animals are allowed, beyond is strictly for human habitation. In the line of the Shah Ksew, about half way along the wall, is the Rishot Blei, a column that serves religious rather than structural functions (this column can be seen in the front part of the traditional houses as shown in Figure 1 and Figure 5). The outermost part of the living area, known as Neng Pei is according to Mawrie [3], the last part of the house that strangers may have access to. Beyond this, is the Rympei, which is the innermost part of the house and the private family area, where the family worships and also where the oral histories and traditions of the people are passed down through the generations. The sleeping areas are called Iing Kyndong. Usually there is a small window-opening on one side of the building known as Pongshai.

As a result of the high precipitation in the area the houses are usually placed on short columns to improve aeration of the supporting wooden members and reduce decay and prevent rodents gaining easy access to buildings.

Although Gurdon [4] described the traditional houses as being inferior to those being built by new Christian converts whose house were more elegant and 
better planned. The performance of such buildings during the 1897 Shillong earthquake, however, did not support such assertion. His opinions were most likely based on aesthetic and sociological factors rather than structural ones.

\subsection{Structural make-up of the traditional houses}

The structural system consists mainly of post and beam timber frames having pillars buried into the ground. The floor is supported at intervals by limestone or wooden pillars called Mawkhrum (Stone-underfloor). The skeletal frame of the

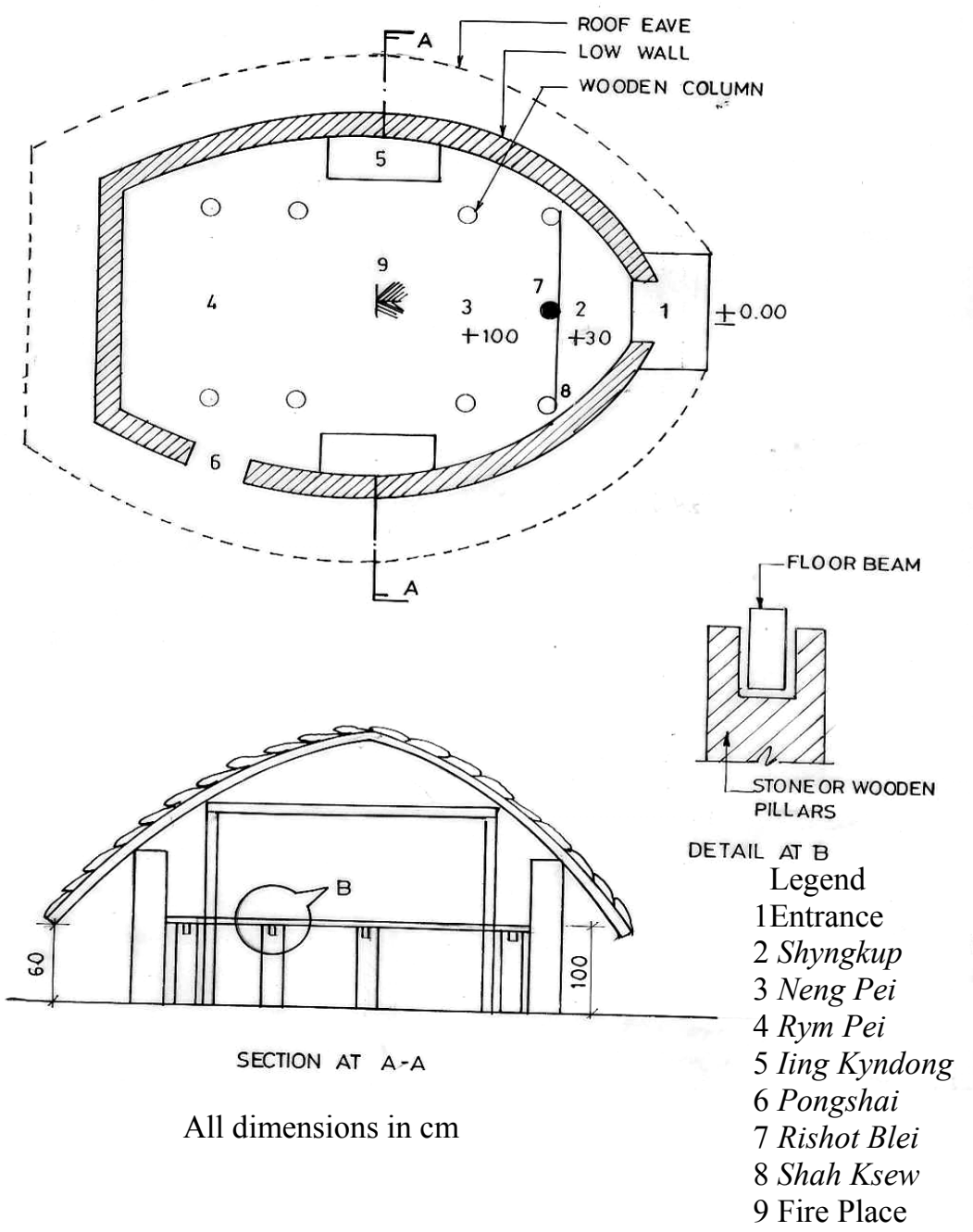

Figure 1: Layout of traditional Khasi house. 


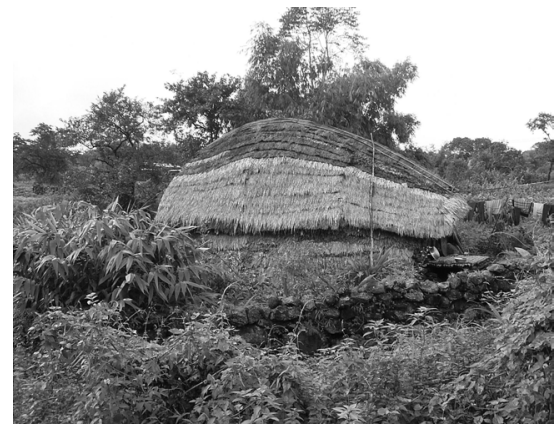

Figure 2: Side view of traditional Khasi house.

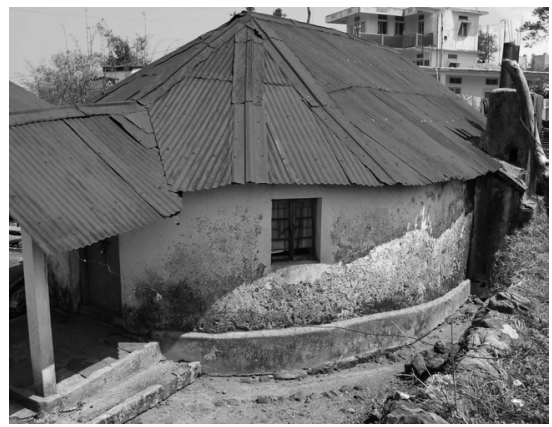

Figure 4: An upgraded traditional Khasi house.

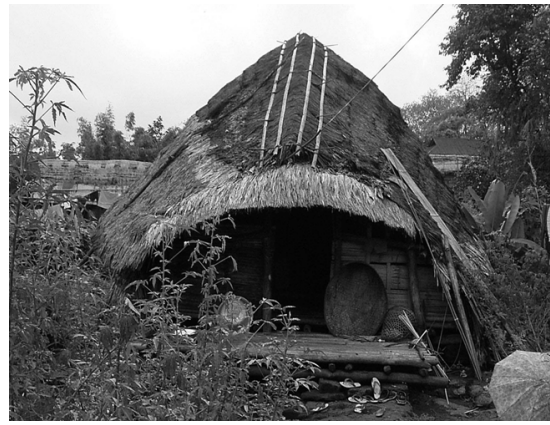

Figure 3: Front view of traditional Khasi house.

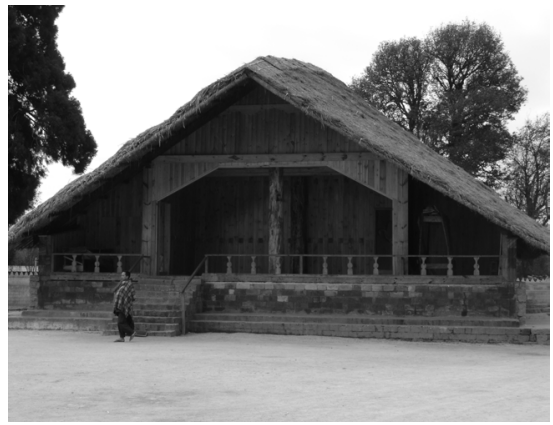

Figure 5: $\quad$ The Iing Sad.

Iing Sad is as shown in Figures 6 and 7. Figure 7 also illustrates the floor support details of the construction. The wooden pillars in the Iing Sad are however encased in limestone almost to plinth level to protect them from attacks by insects and deterioration from moisture absorption. The rafters (Figures 8-10), as in other parts of the construction are connected with a system of grooves and tongues, twigs and ropes and in some cases wooden studs. Nails are not used as the use of nails is a traditional taboo among the Khasi people. Other taboos of the people that are related to building construction include;

- not to build houses at the extreme summit of hills,

- not to build houses with stone walls on four sides,

- not to cut trees from sacred forests,

- $\quad$ not to use more than one type of wood to build the fender surrounding the hearth.

It is possible that some of these taboos might have evolved as a result of past experience on building performance in various conditions including earthquakes. It must however be stated that most of taboos, especially that of not using nails in constructions have faded and are hardly evident in conventional constructions. 


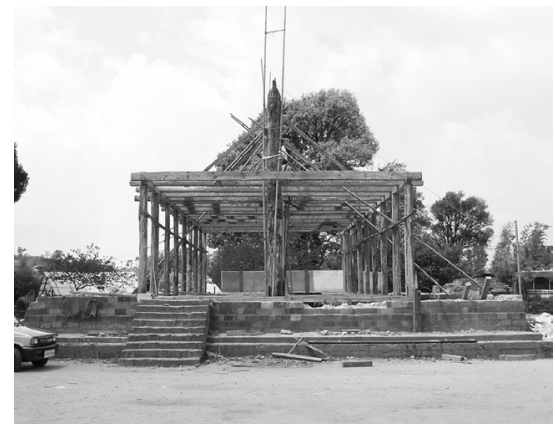

Figure 6: Structural framework of the Iing Sad.

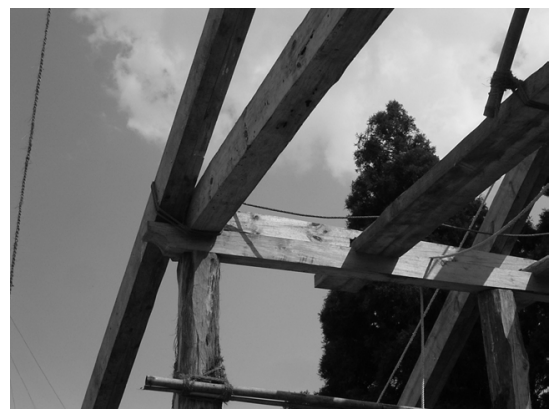

Figure 8: Rafter, beam and post joint detail of the Iing Sad.

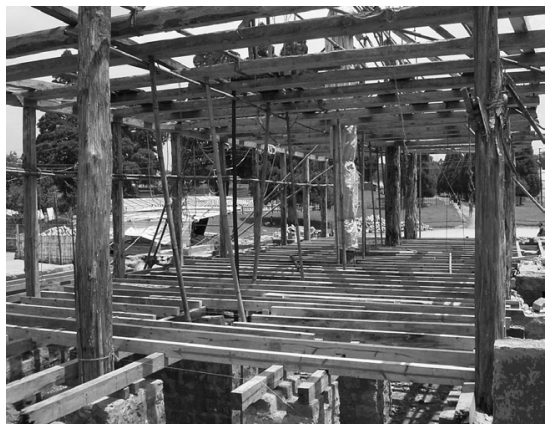

Figure 7: Beam and post system of the Iing Sad showing the floor support details.

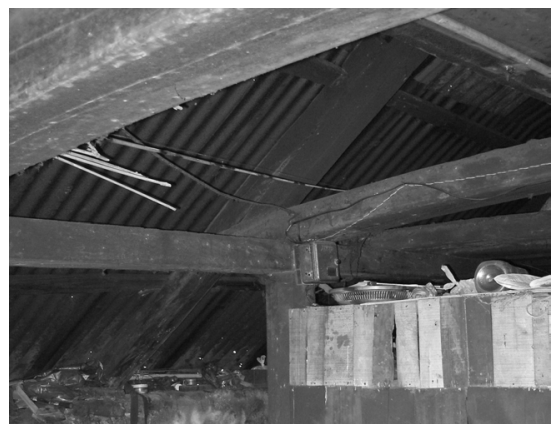

Figure 9: Rafter, beam and post junction of a traditional house.

It was observed that the middle portions of the main beams at the front, middle and back parts of the traditional constructions are slightly curved upwards (this can be seen in Figures 9 and 11). The beams towards the innermost parts of the house were more closely spaced than those at the front parts. The main living areas thus seemed better tied together.

The rafters extend beyond the inner frameworks that serve as walls of the main living areas (Figure 12). The outer walls of the buildings are built close to the edge of the eaves and are usually less than one metre high. Figure 13 shows the outer walls, slightly beyond the inner wall of a traditional building. The main frames of the buildings are structurally independent of the walls and would be unaffected even if the walls fail as shown in Figure 12.

In several parts of the study area it was noticed that some of the traditional buildings are being pulled down to make way for new constructions. Some of the new constructions were made without regards for modern building regulations and close evaluations show that the older construction would be safer if an earthquake occurs. This development is quite noticeable in Sohra. 


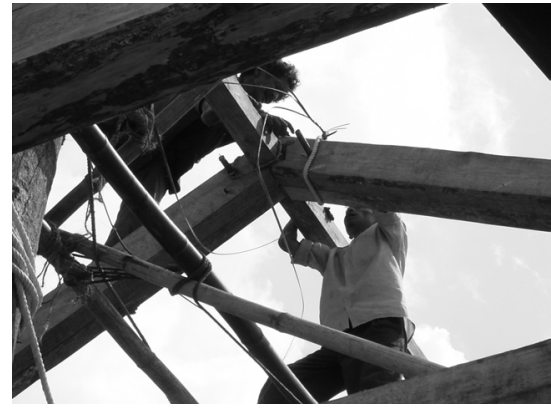

Figure 10: Framework for the ridge of the roof.

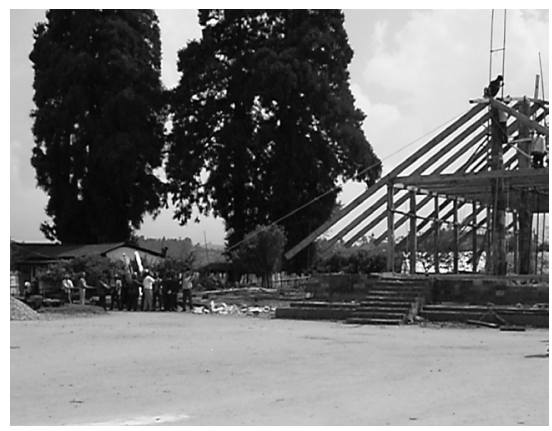

Figure 12: Roof rafters with eaves projecting well beyond main timber frameworks.

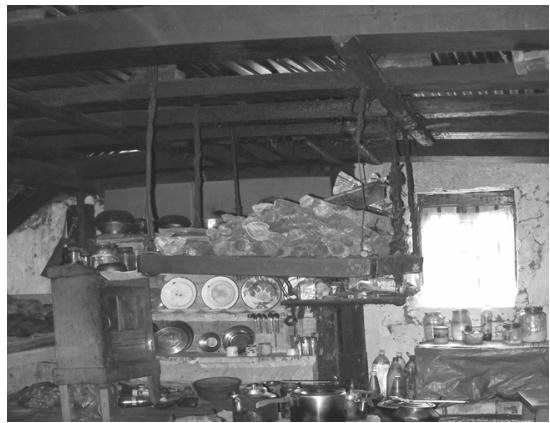

Figure 11: Closely spaced beams at inner parts of the Building.

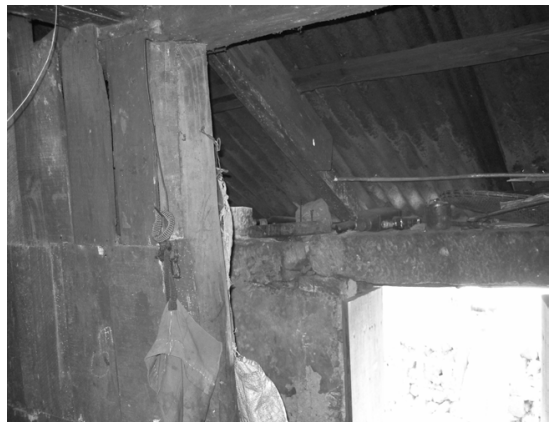

Figure 13: Roof rafters of traditional house are structurally supported by timber frame.

\subsection{Evaluation of traditional Khasi houses for earthquake resistant features}

Timber framed structures in many earthquakes prone countries are known to possess earthquake resistant features. The general configuration of the traditional Khasi houses indicates that they have inherent earthquake resistant characteristics. Mattur and Goel [5] observed that houses made with wooden posts and rafters tied together with roof made of thatch or any such lighter material and panel wall in leaves, grass, and reed or split bamboo with or without mud plaster were resistant to earthquake stresses to a great extent.

The structural framework of the buildings are separated from walls and well tied together, while still maintaining good flexibility. During moderate to large earthquakes, variant of the buildings with stone walls may have wall failures due to out of plane loading, thereby falling outwards but the roof which is held up on wooden columns remain intact since they are supported by the timber frame rather than the stone walls. The occupants are thus protected since the building 
maintains its integrity. The roofs are usually made of light materials, therefore fatalities from falling roof would be expected to be minimal. Placing the buildings on short columns would substantially reduce the effect of lateral loading on them and protect them from high amplitude and high frequency motions.

They are symmetrically shaped with negligible sharp corners. Modern earthquake resistant codes acknowledge the importance of symmetry in earthquake resistant designs. The oval shape of the traditional buildings would result in the avoidance of stress concentrations at corners, which is a major factor in failure at wall corners, especially around beam-column junctions. The aerodynamic shape of the buildings as shown in Figures 2 and 3 would aid the performance of the buildings in the windy terrain of the Shillong plateau and enhance its resistance to the uplifting of roofs and houses by wind.

A close observation of the traditional taboos shows that some of them have implications for the performance of the traditional constructions during earthquakes. The practice of not using nails in house construction found among the Khasis is similar to the traditional construction practices in some parts of China, where mortised joints are mainly used. This is believed to increase the energy dissipation of the joints and it allows the structure to deform and redistribute the lateral loads exerted on the frame as described by Meyer and Ochendorf [6]. The tongues and grooves allows for sliding of building components and a dissipation of seismic loading on such components. Lagenbach [7] concluded that the most important protective characteristic of traditional building may be its ability to dissipate earthquake energy over a long period without rapid structural degradation. He further stated that in traditional building constructions that normally make use of primitive materials and means of construction, rigidity carries the potential for destruction since the more rigid a building is, the stronger it must be to avoid fracture. The traditional materials do not usually possess the required strength. Hence, flexibility was necessary. Not having buildings at summit of hills as practiced by the Khasis in times past, is recommended in modern building codes in earthquake prone areas, especially those where there is danger of liquefaction and landslide. The Shillong plateau is one of such areas as exemplified in the great earthquake of 1897.

\subsection{Conventional building practices in Shillong}

The large scale destruction of houses during the 1897earthquake, led to the adoption of a new type of building style as was the case in Portugal after the devastating earthquake of 1755 as reported by Gulkan and Langenbach [8]. It is normally referred to as the Assam type house. It is a timber framed structure and is at present the standard housing system in the North Eastern part of India although reinforced concrete structures are becoming popular. Some of the pre1897 structures rebuilt with the Assam type construction include the chief commissioner's residency and the All Saints church (Figure 14). Some similarities can be found in the traditional buildings and the Assam type construction. The two types are on elevated short pillars of stone masonry or timber (Figure 15). They are both made up of timber frames. The Assam type 
buildings are however, engineered construction where-in modern design and analytical techniques are applied in their construction.

The walls contain ekra or bamboo infills that are then covered by lime mortars. The infills however, must be regularly inspected for decays and insect attacks which may affect their integrity. In recent times the walls of the Assam type buildings, up to sill level, are protected by constructing them from hollow concrete bricks or coverings of tin sheet. Chicken wire meshes are also replacing the Ekra infill. The Assam type of buildings has been shown to be flexible and responsive to ground motion. They have performed creditably during earthquakes $[9,10]$.

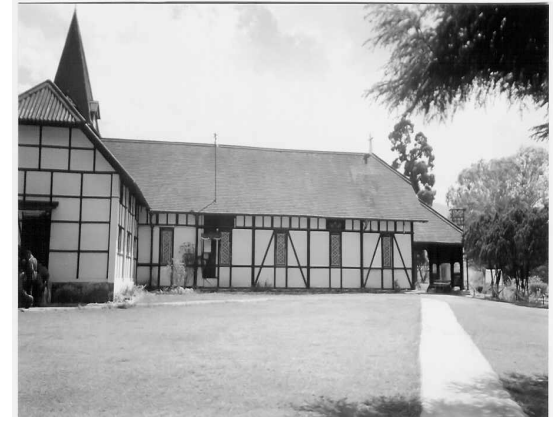

Figure 14: New All Saints church rebuilt after the 1897 earthquake.

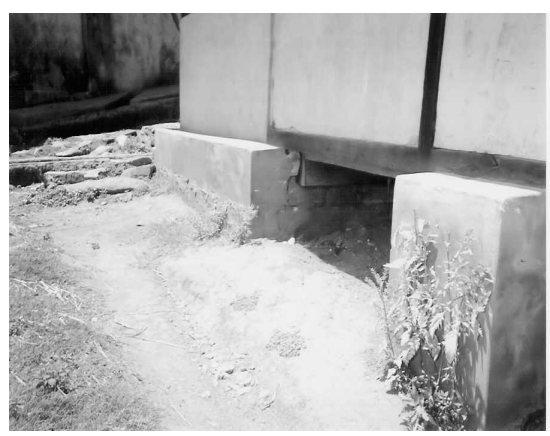

Figure 15: Base of typical Assam type house raised above the ground.

\section{Conclusions}

This study has shown that traditional constructions in Shillong have some of the earthquake resistant features, inherently. Such features have been described and needs to be further studied analytically and by full scale testing in the laboratory so that the useful concepts may be incorporated into modern construction practices. Experience all over the world has shown that traditional building construction methods, which have evolved over a long period, could enhance better understanding of possible solutions to problems that confront mankind at present time. It is also possible to upgrade the traditional buildings to meet modern housing requirement without sacrificing their beneficial features while taking full cognizance of the cultural practices of the occupants.

\section{Acknowledgements}

This study was sponsored by the Council for Scientific and Industrial Research, India and the Academy of Sciences for the Developing World, Italy, as part of the CSIR-TWAS Postdoctoral research fellowship awarded to Dr. B. I. O. Dahunsi of the Department of Civil Engineering, University of Ibadan, Nigeria, 
under the supervision of Dr. A. K. Mittal at the Central Building Research Institute, Roorkee, India. The authors also appreciate the assistance of the following individuals during the field trips and investigations; Architects Donald Siem and Aiban Mawkhroh and Mr. Bantehsonglang Blahwar.

\section{References}

[1] Ambraseys, N., and R. Bilham, MSK Isoseismal intensities evaluated for the 1897 Great Assam Earthquake, Bull. Seism Soc. Am. 93 (2) 655-673. 2003

[2] Satyabala, S.P., The Historical earthquakes of India, In Intl. Handbook of Earthquake and Engineering Seismology. IASPEI Handbook, part A. Academic press. 206p. 2002

[3] Mawrie, L.H.O. The Challenge of Destiny. www.khasi.ws/destiny.htm.

[4] Gurdon, P.R.T. The Khasis, E book \#12786, the project Gutenburg E book. www.gutenberg.net. 117p. 2004.

[5] Mathur, V.K. and N. Goel. Skeleton System- an Approach for Construction of Rural Buildings in Earthquake Prone Areas. Proc. 12 world conf. on Earthquake Engineering, Paper 2064, 7p. 2000

[6] Meyer P. and J. Ochsendorf. Traditional Rural Housing in the Seismically Active Northern Yunnan. Report of China Trip. 11p. 2005.

[7] Langenbach, R. Intuition from the Past: What We Can Learn from Traditional Construction in Seismic Areas. Proceeding, International Conference on the Seismic Performance of Traditional Buildings, Istanbul, Turkey. 22p. 2001.

[8] Gulkan, P. and R. Langenbach, The Earthquake Resistance of Traditional Timber and Masonry Dwellings in Turkey. Presented at the $13^{\text {th }}$ World Conference on Earthquake Engineering. Vancouver, Canada. 15p. 2004.

[9] Suresh, V. Promoting Safer Building Construction. www.adpc.net/audmp/ rllw/PDF/PSB.pdf. 2003.

[10] Dahunsi, B. I. O. and A. K. Mittal, Prospect of Traditional Earthquake Resistant Construction for Rural Areas. Proc. International Conference on Earthquake Engineering, February 25-26 SASTRA Deemed University, Thanjavur, India. pp 577-590. 2006. 